\title{
Modificatie, substitutie of uitbreiding? Over de articulatorische karakteristiek en classificatie van uitspraakfouten van leerders van het Nederlands als vreemde taal
}

\begin{abstract}
The aim of this article is to discuss the problem of different types of pronunciation errors. The study is based on errors made by Polish native speakers learning Dutch. Drawing on current publications concerning the approaches to pronunciation errors classification, it is argued that the existing classifications fail to cover the full spectrum of the problem and to analyze the complexity of the errors themselves. They also are not appropriate to be used in the classroom. In response to weak points of the existing classifications and taking into account actual teaching needs, a new approach is proposed which consists of four modules and is more analyzing (than classifying) in nature. Finally, five examples of common pronunciation errors are first classified and analyzed according to existing classifications and subsequently to the new approach in order to demonstrate that the proposed method indeed allows to evaluate the error in a more detailed way and is therefore more suitable for pronunciation didactics.
\end{abstract}

Keywords: pronunciation error, classification of pronunciation errors, analysis, didactics of pronunciation, Dutch, Polish

\section{Inleiding}

De onderhavige bijdrage vloeit voort uit onderzoek naar de uitspraak van Nederlandse klinkers dat tussen 2009 en 2014 door de auteur aan de Universiteit van Wrocław is uitgevoerd. Bij de uitwerking van het theoretische kader van dit onderzoek zijn verschillende classificaties van uitspraakfouten onderzocht (sommige ervan zijn nader besproken in punt 3.1) maar die bleken allemaal te typologisch georiënteerd en te oppervlakkig te zijn om de brede waaier aan uitspraakfouten in het onderzoekscorpus adequaat te classificeren en te analyseren. Om die reden 
moest een nieuwe benadering worden ontworpen die aan een belangrijke voorwaarde voldeed: de mogelijkheid om de classificatie praktisch toe te passen in de didactiek van de uitspraak. De aanpak die uiteindelijk voor de doeleinden van dit onderzoek is ontwikkeld, wordt hier gepresenteerd en ter discussie gesteld. Vanzelfsprekend mag het werk aan dit model niet als voltooid worden beschouwd omdat tot nu toe alleen maar klinkers onderzocht waren en omdat het model nog niet empirisch werd uitgetest.

$\mathrm{Na}$ de afbakening van het onderwerp (punt 2) en de status quaestionis (punt 3) volgt een bespreking van de uitgangspunten en de aannames van de nieuwe aanpak. In de volgende stap worden de basis en de veronderstellingen van de aanpak besproken (punt 4). Vervolgens wordt getoond hoe de uitspraakfout (en) in het kader van die aanpak in 4 stappen geanalyseerd en geclassificeerd wordt (worden) (punt 5). Afsluitend (punt 6) behandelen wij enkele voorbeelden van fouten in de uitspraak van klinkers volgens enkele traditionele benaderingen en met de nieuwe aanpak om uiteindelijk enkele conclusies te trekken en mogelijke suggesties voor verder onderzoek te formuleren.

\section{Onderzoeksonderwerp}

\subsection{Uitspraakfouten en error analysis}

Sinds Weinreich in de jaren '50 zijn eerste classificatie van uitspraakfouten presenteerde (Weinreich 1953: 18-19), zijn in de vakliteratuur meerdere soortgelijke classificaties voorgesteld.De meeste dateren uit de jaren ' 60 en ' 70 , dus uit de periode waarin de error analysis ${ }^{1}$ een van de leidende tendensen was in het kader van Second Language Acquisition research (SLA) (vgl. Moulton 1962; voor het Engels en Duits, Stockwell \& Bowen 1975; voor het Engels en Spaans, Tesch 1978, Weinreich 1953: 14-22). Ook in Poolse publicaties uit de jaren '70, die door Poolse germanisten zijn uitgewerkt, zijn classificatiepogingen op het gebied van uitspraakfouten te vinden (Prędota 1971; Szulc 1973; voor het Pools en Duits). De classificaties hebben een verschillende graad van nauwkeurigheid en leggen nadruk op verschillende zwaartepunten, maar ze delen allemaal een gezamenlijk kenmerk: ze zijn namelijk allemaal theoretisch van aard omdat ze gebaseerd zijn op verschillen tussen fonologische systemen, die uit abstracte eenheden (zgn. fonemen) bestaan. Dit makte dat ze beter toegepast konden worden op taaltypologisch gebied dan direct in de didactiek van uitspraak van een vreemde taal. Dit gebrek aan praktische toepasbaarheid is ook de reden waarom de interesse voor error analysis in het uitspraakonderwijs kleiner geworden is (vooral ten gunste

${ }^{1}$ Zie Corder (1967) en Corder (1981) voor de basisprincipes van error analysis en Spillner (1991) voor uitgebreide bibliografie van de discipline. 
van het onderzoek naar de interlanguage ${ }^{2}$ ). Toch worden er de laatste jaren weer pogingen op dit gebied ondernomen (zie bijv. Kühn 2010, voor Romaanse talen).

\subsection{Onderzoek naar de uitspraak(fouten) in de neerlandistiek}

In de laatste twee decennia werd er in de neerlandistiek veel aandacht aan uitspraak en uitspraakonderwijs besteed. Wij beschikken, naast recente fonetische studies van het Nederlands in de Lage Landen (o.a. Smakman 2006, Heuven \& Velde 2010) die als vergelijkingsbasis kunnen worden genomen, en de uitspraakleerboeken (Beheydt, Dirven \& Kaunzner 2011; Blomme, Nordin \& Potargent 2009; Veen 2011; Kampen, Olijhoek \& Stumpel 2011; Sleeuwen \& Spaan 2013), ook over talrijke publicaties over uitspraakonderwijs in het kader van NT2 en NVT (neerlandistiek in het Centraal-Oost Europa inbegrepen). Hiertoe horen o.a. verschillende theoretische of theoretiserende bijdragen rond uitspraakonderwijs (Lowie 2004; Nagy 2006; Rasier 2008 \& 2011; Beheydt 2011; Smakman 2016; Czerwonka 2010), benaderingen over uitgekozen segmentale en suprasegmentale fonologische en fonetische kenmerken waarin het Nederlands met een andere taal vergeleken wordt (Nagy 2015; Kostelecká 2012) voor het Nederlands en het Tsjechisch, Czerwonka (2010, 2011, 2012 \& 2013) voor het Nederlands, Duits en Pools, Vriendt (1993) voor het Nederlands en Slavische talen, Hiligsmann (1998 \& 1999), Hiligsmann \& Rasier (2006), Baelen, Hiligsmann \& Rasier (2008) voor het Nederlands en het Frans, Heuven (2010) voor het Nederlands en het Turks en thematische nummers van tijdschriften en andere publicaties in hun geheel gewijd aan het uitspraakonderwijs van het Nederlands (o.a. Levende Talen 78, Lage Landen Studies 2, Vakwerk 4). Toch is in geen van de bovengenoemde bronnen de poging ondernomen om de uitspraakfouten van buitenlandse leerders en studenten van het Nederlands vanuit een holistisch perspectief te benaderen dat zich wel in de uitspraakdidactiek van het Nederlands zou laten toepassen.

\subsection{Afbakening van het onderwerp en probleemstelling}

In deze bijdrage wordt het probleem van de omschrijving en classificatie van uitspraakfouten gepresenteerd die een praktische didactische toepasbaarheid heeft en als een aanvulling gezien kan worden op de door Rasier (2008) voorgestelde overgang van uitspraakonderzoek naar uitspraakonderwijs. De aanpak die hier gepresenteerd wordt, is op een analyse van daadwerkelijk genoteerde uitspraakfouten gebaseerd en niet op theoretische verschillen tussen foneemsystemen - dit in tegenstelling tot de classificaties uit de jaren ' 60 , ' 70 en ' 80 genoemd in 2.1

\footnotetext{
${ }^{2}$ Zie Selinker (1972). Niet te verwisselen met de tussentaal in Vlaanderen.
} 
en 3.1. In deze aanpak wordt een uitspraakfout telkens in vier stappen vanuit verschillende gezichtspunten steeds nauwkeuriger geanalyseerd. Op die manier kan een aanpak voor de uitspraakfouten worden uitgewerkt die beter in de didactiek van de uitspraak toe te passen valt, o.m. door het identificeren van die processen die voor het ontstaan van de fout verantwoordelijk zijn, en door het aanwijzen van gebreken in het articulatieproces die vervolgens in de uitspraakcolleges gecompenseeerd kunnen worden.

\section{Status quaestionis}

\subsection{Bestaande classificaties van uitspraakfouten}

Moulton, een van de classici van vergelijkende taalkunde, stelde vast dat er twee methodes zijn om een classificatie van uitspraakfouten samen te stellen:

First, a few words on two methods which can be employed in writing a contrastive study which will be useful to foreign language teachers. One approach is purely pragmatic. The investigator simply listens to the pronunciation errors [...]. He notes them down and then tries to arrange them in an order which will be useful to his readers. A second approach - and one more interesting to the linguist - is more theoretical. Here the investigator analyzes the phonological structures of the two languages, notes the points of agreement and disagreement between them, and then, on the basis of the observed disagreements, tries both to predict the errors which a learner will make [...] (Moulton 1962: 101).

De eerste methode houdt dus in dat de uitspraakfouten in het taalgebruik eerst verzameld en daarna ingedeeld worden op basis van praktische criteria. De tweede methode baseert zich daarentegen op de theoretische vergelijking van foneem- of klanksystemen van de twee betrokken talen, wat tot het opstellen van een lijst van verschillen leidt. Die lijst wordt dan gebruikt om fouten in het feitelijk taalgebruik te voorspellen.

Volgens Moulton levert het combineren van beide methodes de beste resultaten op voor het classificeren van uitspraakfouten ("a combination of these two methods leads to the best results", Moulton 1962: 101). Toch baseerde hij zijn eigen classificatie van uitspraakinterferenties tussen het Duits en het Engels uitsluitend op een theoretische vergelijking van de foneemsystemen van beide talen. De vraag rijst nu wat de meest gebruikelijke classificaties zijn van uitspraakinterferenties. Hierna laten we er een aantal revue passeren. 
Methode 1
Taalgebruik
Classificatie van fouten

\subsubsection{Weinreich}

Weinreichs werk Languages in Contact: Findings and Problems (1953) was niet alleen een hoeksteen voor het onderzoek naar multilingualisme en taalcontact, maar leverde tevens de eerste classificatie van uitspraakfouten op. Deze ontstond op analytische basis, dat betekent "not from the raw data directly, but from their phonetic analysis" (Weinreich 1953: 19). Dat leidde hem tot een vierdelige typologie (Weinreich 1953: 18-19): ${ }^{3}$

(1) Under-differentiation of phonems occurs when two sounds of the secondary system whose counterparts are not distinguished in the primary system are confused [...]. Zo bijvoorbeeld is er onderdifferentiëring van de Nederlandse gespannen [e] als een Poolse leerder die uitspreekt als een ongespannen $[\varepsilon]$ klank.

(2) Over-differentiation of phonems involves the imposition of phonemic distinctions from the primary system on the sounds of the secondary systems, where they are not required [...]. Als voorbeeld kan hier de overdifferentiatie in de $\mathrm{Ne}$ derlandse fricatieven onder invloed van Poolse fricatieven fungeren.

(3) Reinterpretation of distinctions occurs when the bilingual distinguishes phonemes of the secondary system by features which in that system are merely concomitant or redundant, but which are relevant in his primary language [...]. Zo hebben de Poolse leerders van het Nederlands voorkeur voor de tong-r die in het Pools als normatief correct beschouwd wordt.

(4) Actual phone substitution, in the narrow sense of the term, applies to phonemes that are identically defined in two languages but whose normal pronunciation differs [...]. Zo bijvoorbeeld is er zowel in het fonologisch systeem van het Pools als ook in het het fonologisch system van het Nederlands de glijklank

\footnotetext{
${ }^{3}$ Zie ook Weinreich (1953: 14-22) voor een bewerkte en uitgebreidere versie.
} 
/j/ aanwezig, maar in het Pools wordt hij met meer spreiding van de lippen uitgesproken.

Omdat Weinreich het foneem als door een fout getroffen eenheid beschouwt en de fouten zonder hun invloed op de betekenis van het woord onderzoekt, kunnen we aannemen dat het hier om gedetailleerde indeling van louter fonetische uitspraakfouten gaat.

\subsubsection{Moulton, Stockwell \& Bowen en Tesch}

Anders dan bij Weinreich zijn de classificaties van Moulton (1962), Stockwell en Bowen (1975) en Tesch (1978) ontstaan op basis vergelijking van "phonological structures of the two languages" met daarbij de vaststelling van "the points of agreement and disagreement between them". Het feitelijk taalgebruik wordt hier dus niet geanalyseerd. Als materiaal voor de vergelijking zijn de volgende talen genomen:

- Engels en Duits (Moulton),

- Engels en Spaans (Stockwell en Bowen),

- Engels, Duits en enkele andere kleinere talen (Tesch).

Alle drie de classificaties zijn algemeen-typologisch bedoeld, daarbij wordenvier hoofdtypes uitspraakfouten onderscheiden: fonologische fouten (het veranderen van foneem leidt tot verandering van betekenis van het woord, bijv. ziet [zit] i.p.v. zit [zit]), fonetische fouten (het veranderen van foneem leidt niet tot verandering van de betekenis van het woord, bijv. het woord tas word uitgesproken als [tas] i.p.v. [tas]), allofonische fouten (het onjuiste allofoon wordt gebruikt, bijv. kort gespannen [i] i.p.v. lange gespannen [i:] voor r) en distributie-fouten (de distributie van een foneem is niet juist, bijv. heldere 1 i.p.v. donkere 1 aan het eind van het woord). Een meer gedetailleerde indeling per type wordt niet gedaan.

\subsubsection{Prędota}

De classificatie van Prędota (1971) neemt de indeling van uitspraakfouten van Weinreich als beginpunt maar is gebaseerd op de vergelijking van foneemsystemen en heeft daardoor een theoretisch karakter. De belangrijkste factor is de kwalitatieve en kwantitatieve vergelijking van distinctieve kenmerken van de fonemen. Op basis van deze kwalitatief-kwantitatieve verhouding van distinctieve kenmerken onderscheidt Prędota transfer (een positief proces dat voorkomt als kenmerken van fonemen in beide te vergelijken talen identiek zijn en het aantal ervan ook identiekis) en vier soorten fouten (Prędota 1971: 139):

1. Unterdifferenzierung (onderdifferentiatie, d.w.z. alle gezamenlijke kenmerken van een foneem in de vreemde taal en moedertaal zijn identiek maar het 
aantal distinctieve kenmerken in de vreemde taal is groter dan het aantal distinctieve kenmerken in de moedertaal);

2. Überdifferenzierung (overdifferentiatie, d.w.z. alle gezamenlijke kenmerken van een foneem in de vreemde taal en moedertaal zijn identiek maar het aantal distinctieve kenmerken in de vreemde taal is kleiner dan het aantal distinctieve kenmerken in de moedertaal);

3. Unterdifferenzierung mit Merkmalsexklusion (onderdifferentiatie met kenmerkuitsluiting; d.w.z. het aantal kenmerken van de vreemde taal en de moedertaal is gelijk maar die kenmerken zijn niet identiek of niet alle gezamenlijke kenmerken in de moedertaal en vreemde taal zijn identiek en het aantal kenmerken in de vreemde taal is groter dan in de vreemde taal);

4. Überdifferenzierung mit Merkmalsexklusion (overdifferentiatie met kenmerkuitsluiting; d.w.z. niet alle gezamenlijke kenmerken in de moedertaal en in de vreemde taal zijn identiek en het aantal kenmerken van de vreemde taal is kleiner dan in de moedertaal).

\subsubsection{Szulc}

De classificatie van Szulc (1973) valt grotendeels samen met de classificatie van Moulton (1962): op basis van verschillen tussen foneemsystemen worden er fonologische, fonetische en distributionele fouten onderscheiden. Maar Szulc voert een belangrijk nieuw element in, dat de andere classificaties buiten beschouwing hebben gelaten: de invloed van de grafemiek. Szulc voorspelt het volgende: "Die beim Muttersprachler automatisierte Assoziation zwischen einem Graphem und einem bestimmten Laut führt ebenso automatisch zur Bevorzugung eines bestimmten Allophons, bzw. Phonems bei der akustischen Realisierung des graphematischen Systems der ZS [ZS - Zielsprache, ZC]" (Szulc 1973: 116). Dit komt voor bijvoorbeeld in het geval van het u-grafeem waarmee in het Nederlands het foneem [y] of [Y] weer-

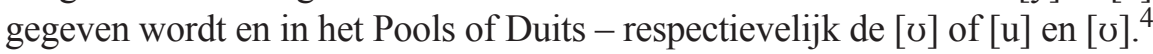

Szulc beschouwt grafemische fouten als een aparte categorie, maar in feite staan soortgelijke fouten vaak in nauw verband met fonetische, fonologische of distributionele fouten. Eigenlijk is hier sprake van een dubbele fout of een fout die extra grafemisch ondersteund is. Zo wordt bijvoorbeeld in de uitspraak van Poolstaligen i.p.v. de Nederlandse [y] de Poolse [u] gerealiseerd niet alleen omdat de [y] in het klanksysteem van het Pools niet bestaat, maar vooral omdat in de Poolse spelling hier een $[\mathrm{u}]$ suggereert.

${ }^{4}$ Wat Szulc in zijn classificatie buiten beschouwing laat, is het feit dat ook de vreemde taal de bron van grafemische foten zijn kan. In zo'n geval is er sprake van "eine falsche Verallgemeinerung von Regeln" van de vreemde taal (Rausch \& Rausch 2002: 51) die voorkomt als grafemisch de weergave van twee fonemen samenvalt (zoals bijv. in het Nederlands de $<\mathrm{ij}>$, die meestal met de tweeklank te associëren valt, maar af en toe ook met een [ə] (tegelijk vs. mogelijk). 


\subsubsection{Kühn}

De laatste classificatie van uitspraakfouten die te bespreken valt, is de classificatie van Kühn, voorgesteld in haar werk Kontrastive Phonetik der romanischen Sprachen (2010). Deze classificatie is de enige die ontstaan is conform de theoretischpragmatische werkwijze die door Moulton aanbevolen werd: de basis vormde hier een theoretische vergelijking tussen foneemsystemen die vervolgens geverifieerd werd door analyse van fouten in feitelijk taalgebruik (en dit voor enkele taalparen). Op die manier is een classificatie ontstaan die (naast transfer) de volgende uitspraakfouten omvat (vgl. Kühn 2010: 115; vertaling en commentaar door ZC):

1. Substitutie van een klank in de vreemde taal door een andere (vanwege grote verschillen tussen de vreemde taal en de moedertaal);

2. Splitsing van een klank vanuit de vreemde taal in twee klanken vanuit de moedertaal (omdat de vreemde klank in de moedertaal niet bekend is);

3. Splitsing van een klank vanuit de vreemde taal in drie klanken vanuit de moedertaal (omdat de vreemde klank in de moedertaal niet bekend is);

4. Verlies van een klank (de onbekende vreemde klank wordt helemaal niet gerealiseerd);

5. Combinatie van twee klanken tot één (twee klanken van de vreemde taal worden gecombineerd tot één klank uit de moedertaal);

6. Fouten verbonden met de kwaliteit: kwaliteit-verlies (de klank van de vreemde taal wordt zonder spanning gerealiseerd omdat de spanning in de moedertaal geen distinctief kenmerk is) of kenmerktoevoeging (de ongespannen klank in de vreemde taal wordt gespannen gerealiseerd omdat spanning een distinctief kenmerk is in de moedertaal).

\subsubsection{Synthese}

In de hiernavolgende synthese bieden we een overzicht van de classificaties met een beoordeling van hun didactisch potentieel. De kwestie van didactisch nut is vooral ermee verbonden, hoe makkelijk een classificatie in het didactisch proces van uitspraak kan worden toegepast en hoe begrijpelijk ze is voor een taalgebruiker die niet over fonetische/fonologische kennis beschikt.

Tabel 1. Synthese van classificaties met hun didactisch nut

\begin{tabular}{|c|l|l|l|c|}
\hline & \multicolumn{1}{|c|}{ Auteur } & \multicolumn{1}{|c|}{ Basis/karakter } & \multicolumn{1}{|c|}{ Interessante punten } & Didactisch nut? \\
\hline 1. & Weinreich & taalgebruik/typologisch & $\begin{array}{l}1^{\mathrm{e}} \text { classificatie; proces } \\
\text { achter de fout }\end{array}$ & $?$ \\
\hline 2. & $\begin{array}{l}\text { Moulton } \\
\text { Stockwell/ } \\
\text { Bowen } \\
\text { Tesch }\end{array}$ & foneemsysteem/typologisch & $\begin{array}{l}\text { onderscheid fono- } \\
\text { logisch/fonetisch/ } \\
\text { distributioneel }\end{array}$ & + \\
\hline
\end{tabular}




\begin{tabular}{|c|l|l|l|c|}
\hline 3. & Prędota & foneemsysteem/typologisch & uitbreiding Weinreich & - \\
\hline 4. & Szulc & foneemsysteem/typologisch & factor grafemiek & + \\
\hline 5. & Kühn & $\begin{array}{l}\text { foneemsysteem+klanksysteem } \\
\text { +taalgebruik/didactisch }\end{array}$ & $\begin{array}{l}\text { articulatorisch proces } \\
\text { achter de fout }\end{array}$ & +++ \\
\hline
\end{tabular}

De classificatie van Weinreich steunt op taalgebruik en heeft een typologisch karakter. Het was de eerste classificatie die verder onderzoek heeft geïnspireerd. Belangrijk was ook dat Weinreich het proces dat voor het ontstaan van de fout verantwoordelijk was, als basis nam voor zijn classificatie - op die manier zou zijn classificatie wel toepasbaar kunnen zijn in de didactiek. De vraag is of ze duidelijk genoeg is voor een beginnende taalgebruiker die niet over voldoende fonetische/fonologische kennis beschikt. Nemen we als voorbeeld de volgende situatie: de moedertaal (L1) beschikt over een $[\varepsilon]$ en de vreemde taal (L2) - over het distinctieve fonemenpaar $[\varepsilon]$ en [ $\varepsilon$ :]. Als de moedertaalspreker van deze L1, in de L2 [ $\varepsilon$ :] door $[\varepsilon]$ vervangt, hebben we met een fout te maken die wij als onderdifferentiatie kunnen classificeren. Zou een dergelijke uitleg inzichtelijk genoeg zijn voor de taalgebruiker? Dat is zeer de vraag. De classificatie van Prędota neemt het idee van Weinreich over naar het niveau van foneemsystemen. Ze is daardoor van beperkt nut voor uitspraakdidactiek.

De classificaties van Moulton, Stockwell en Bowen en Tesch zijn gebaseerd op het vaststellen van verschillen tussen foneemsystemen van talen. Fonemen zijn theoretische eenheden, maar uitspraak is gebaseerd op fonetische kenmerken zoals die zich reëel in de spraakklanken voordoen en niet op fonemen. Om die reden kunnen die classificatie niet direct in de didactiek van uitspraak worden toegepast: uitspraakdidactiek gaat uit van klanken, niet van fonemen. Maar de indeling in fonologische, fonetische en distributionele fouten is opzichzelf wel interessant want het is ook didactisch belangrijk te weten of een verschil betekenisonderscheidend is, d.w.z. of het veranderen van een klank tot verandering in de betekenis van het woord leidt (bijv. [e.n] vs. [عn] vs. [ən]) of niet. De vraag is alleen inhoeverre de fonologische fouten door de context verholpen kunnen worden (zie daarvoor voorbeeld in punt 4.1).

De classificatie van Szulc valt voor een groot deel samen met classificaties van Moulton, Stockwell \& Bowen en Tesch maar voert een interessante nieuwe factor in: de invloed van de grafemiek. Als we er rekening mee houden dat veel uitspraakoefeningen (ten minste gedeeltelijk) op schriftelijk materiaal gebaseed zijn, zal de invloed van de spelling op de uitspraak niet buiten beschouwing mogen worden gelaten.

De classificatie van Kühn is zeker de meest uitgebreide. Dat komt doordat ze ook op analyse van taalgebruik gebaseerd is. Ook lijkt de terminologische kant 
toegankelijker te zijn waardoor de classificatie makkelijker in uitspraakcolleges toepasbaar kan zijn.

\subsection{Kritiek op de bestaande classificaties}

Op basis van de besproken classificaties van fouten kunnen enkele conclusies worden geformuleerd die tegelijkertijd het uitgangspunt voor een nieuwe aanpak zouden kunnen zijn (zie punt 3.3). Ten eerste is het didactisch geen goede keuze om de classificatie uitsluitend op een theoretische vergelijking van foneemsystemen te baseren. Fonemen zijn namelijk abstracte eenheden en de combinatie van distinctieve kenmerken ervan verschilt per taal. Bovendien voert het bestaan van een verschil tussen systemen niet automatisch tot een uitspraakprobleem (bijv. het gebrek aan ontspannen [e] in het Pools veroorzaakt niet dat deze klank in $100 \%$ gevallen door een Poolse ongespannen $[\varepsilon]$ vervangen wordt). Ten tweede zijn de bestaande classificaties (ook die meest uitgebreide van Kühn) vrij oppervlakkig - ze blijven beperkt tot algemene processen die verantwoordelijk zijn voor het ontstaan van de fout of eventueel tot invloed van de fout of woordniveau (invloed op betekenis: fonologisch vs. fonetisch/distributioneel). Ze houden geen rekening met factoren zoals invloed van grafemiek (behalve die classificatie van Szulc, maar hier wordt geen rekening gehouden met de invloed van de spelling van de doeltaal) of invloed van suprasegmentale factoren (klemtoon, intonatie). Ten derde is de bestaande classificatie betrokken op taalparen L1 en L2 en invloed van een andere vreemde taal (L2, L3) die voor een volgende doeltaal geleerd werd (en Nederlands wordt vaak als L3, L4 of zelfs L5 geleerd), wordt helemaal buiten beschouwing gelaten.

\subsection{Hoe kan classificatie van uitspraakfouten beter worden aangepakt?}

Op basis van de vastgestelde gebreken van bestaande classificaties van uitspraakfouten kunnen enkele verbeteringen worden voorgesteld. In plaats van op vergelijking van foneemsystemen zou de classificatie van de fout op vergelijking van articulatorische kenmerken gebaseerd moeten zijn. Uitspraak is immers in de eerste plaats realisatie van articulatorische kenmerken. Bovendien zijn articulatorische kenmerken universeel aangezien ze direct verbonden zijn met de fysiologische bouw van de articulatieorganen). Ze zijn ookgemakkelijker uit te leggen aan een taalgebruiker zonder voorkennis van fonetiek en fonologie. ${ }^{5}$ Het is ook belangrijk dat feitelijk taalgebruik betrokken wordt bij de classificatie want alleen daarin zijn

${ }^{5}$ Zie ook Kostelecká (2010) voor een fonetische vergelijking van het Nederlands en het Tsjechisch vanuit het perspectief van articulatory settings die het nut van articulatorische kenmerken in het uitspraakonderwijs bewijst. 
uitspraakfouten in hun totaliteit vast te stellen. Immers, heel wat uitspraakfouten zijn enkel contextueel vast te stellen (bijv. assimilatiefouten). Bovendien moet de uitspraakfout in het kader van de classificatie vanuit verschillende gezichtspunten worden bekeken, zoals:

- de uitwerking van de fout op het woordniveau (heeft de fout invloed op de betekenis van het woord of niet?),

- het algemene proces dat voor het ontstaan van de fout verantwoordelijk was,

- de concrete verandering van afzonderlijke articulatorische kenmerken die tot ontstaan van de fout hebben gevoerd (in het specifiek).

Ten slotte mogen enkele bijkomende factoren niet buiten beschouwing worden gelaten: de spelling (van de moedertaal, doeltaal en alle andere voor de doeltaal geleerde talen), de suprasegmentale factoren (klemtoon, intonatie) en de invloed van alle andere (vroeger) geleerde talen op de uitspraak in de doeltaal.

Bij de noodzaak om met zoveel factoren rekening te houden dringt de vraag zich op of het voor de uitspraakdidactiek niet zinvoller zou zijn om meer in de richting van een uitgebreide foutanalyse met elementen van classificatie te gaan dan puur classificerend te werken. Hoe dat gedaan kan worden, zal in de volgende paragraaf voorgesteld en nader toegelicht worden.

\section{Analyse van uitspraakfout(en) in 4 stappen (met elementen van classificatie)}

De aanpak die in hiernavolgend gepresenteerd wordt, is uitgewerkt uitgaande van enkele basisprincipes. Ten eerste wordt hier getracht didactisch nuttige aspecten van de bestaande classificaties te gebruiken, bijvoorbeeld het idee van Moulton en Weinreich om fouten in het feitelijk taalgebruik erbij te betrekken of het idee van Szulc om de invloed van grafemiek onder de loep te nemen. Ten tweede wordt hier rekening gehouden met voorgestelde verbeteringen besproken in punt 3.3, met de meeste aandacht voor mate van gedetailleerdheid van de analyse. Dat leidt uiteindelijk tot een analyse in vier stappen (met enkele classificatieopties per stap): in stappen 1 t.e.m. 3 hebben wij met een geleidelijke top-down analyse te maken en in stap vier worden andere factoren bij de analyse betrokken (zoals grafemiek, suprasegementale factoren, invloed van andere talen). Ten derde wordt naar met het oog op het didactisch nut gestreefd, rekening gehouden met de grote verschillen in de fonetische en fonologische voorkennisvan de doelgroep. De bedoeling is om elke analysestap als een aparte module te zien die naar behoefte uitgevoerd wordt.

Voorbeelden en classificatiemogelijkheden die per analysestap ter illustratie gegeven worden, komen uit het proefschrift van de auteur, waarin de theoretische vergelijking en analyse van uitspraakopnames van Nederlandse klinkers door Pools- en Duitstalige studenten Nederlands aan bod komt. 


\subsection{Stap 1}

In de eerste stap wordt de uitspraakfout geanalyseerd vanuit een semantisch oogpunt, d.w.z. vanuit haar invloed op de betekenis van het woord. Wij kunnen fonologische (betekenis veranderende) en fonetische (niet betekenis veranderende) fouten onderscheiden. De verwachting is dat de fonologische fouten wezenlijk zeldener zullen voorkomen dan de fonetische fouten: in ons onderzoekcorpus vormden de fonologische fouten slechts 3,5\% van bijna 1000 geregistreerde fouten). En het aantal fonologische fouten die de betekenis van het hele bericht zouden veranderen, zal nog kleiner zijn (geen enkel geval in het gebruikte corpus). Dat kunnen wijj met een voorbeeld illustreren waarin zelfs twee fonologische uitspraakfouten het bericht niet veranderen omdat ze dankzij de context verholpen kunnen worden.

Bericht: Dit zal een rol spelen. $\quad$ een $\rightarrow$ en $\quad$ spelen $\rightarrow$ spellen

Concreet betekent dit dat deze eerste stap in een snelle analyse tijdens uitspraakcolleges weggelaten mag worden.

\subsection{Stap 2}

In de tweede stap wordt het proces geanalyseerd dat voor het ontstaan van de fout verantwoordelijk was die wij het wezen van de verandering kunnen noemen. Voor de klinkers konden tot nu toe de volgende processen worden vastgesteld ${ }^{6}$ :

Tabel 2. Processen (stap 2)

\begin{tabular}{|c|c|c|c|}
\hline & Proces & Uitleg & Voorbeelden \\
\hline 1. & (klinker)substitutie & $\begin{array}{l}\text { de juiste klinker in de doeltaal wordt } \\
\text { door een andere, onjuiste klinker } \\
\text { (vanuit de L1) vervangen }\end{array}$ & $\begin{aligned} {[\mathrm{I}] } & \rightarrow[\mathrm{i}] \\
{[\mathrm{e} .] } & \rightarrow[\varepsilon]\end{aligned}$ \\
\hline 2. & (klinker)uitbreiding & $\begin{array}{l}\text { voor/na de klinker wordt een glijklank } \\
\text { toegevoegd }\end{array}$ & {$[\mathrm{j}]+[\mathrm{y}]$} \\
\hline 3. & (klinker)verlies/-deletie & $\begin{array}{l}\text { een klinker wordt helemaal niet } \\
\text { gerealiseerd }\end{array}$ & --- \\
\hline 4. & (klinker)toevoeging & $\begin{array}{l}\text { een klank (maar geen glijklank) wordt } \\
\text { na de correcte klinker toegevoegd }\end{array}$ & {$[\mathrm{i}] \rightarrow[\mathrm{i}]+[\varepsilon]$} \\
\hline
\end{tabular}

${ }^{6}$ De lijst is waarschijnlijk niet volledig - het is mogelijk dat ze bij andere taalparen vanwege andere processen verlengd zou moeten worden; zie de classificatie van Kühn voor Romaanse talen, die gedeeltelijk andere processen omvat. 


\begin{tabular}{|c|c|c|c|}
\hline 5. & (klinker)modificatie & $\begin{array}{l}\text { de lengte/duur van de klank wordt } \\
\text { gemodificeerd (maar de klinker blijft } \\
\text { gespannen) }\end{array}$ & $\begin{aligned} {[\mathrm{i}:] } & \rightarrow[\mathrm{i}] \\
{[\mathrm{e}:] } & \rightarrow[\mathrm{e} .] \\
{[\mathrm{o}:] } & \rightarrow[\mathrm{o} .]\end{aligned}$ \\
\hline
\end{tabular}

Er zijn ook de volgende combinaties van twee processen mogelijk:

Tabel 3. Combinaties van processen $(\operatorname{stap} 2)$

\begin{tabular}{|l|l|c|c|}
\hline \multicolumn{1}{|c|}{ Proces } & Uitleg & Voorbeelden \\
\hline 6. & $\begin{array}{l}\text { (klinker)substitutie } \\
+(\text { klinker)uitbreiding }\end{array}$ & $1+2^{7}$ & $\begin{array}{c}{[\mathrm{e} .] /[\mathrm{e}:] \rightarrow[\varepsilon]+[\mathrm{j}]} \\
{[\mathrm{o} .] /[\mathrm{o}:] \rightarrow[\mathrm{o}]+[\mathrm{w}]}\end{array}$ \\
\hline 7. & $\begin{array}{l}\text { (klinker)substitutie } \\
+ \text { (klinker)toevoeging }\end{array}$ & $1+4$ & $\begin{array}{c}{[\varnothing:] \rightarrow[\varepsilon]+[\mathrm{v}]} \\
{[\mathrm{u}:] \rightarrow[\mathrm{o}]+[\varepsilon]}\end{array}$ \\
\hline
\end{tabular}

\subsection{Stap 3}

Terwijl in stap 2 het proces in zijn algemeenheid gekarakteriseerd wordt die voor het ontstaan van de fout verantwoordelijk is, gaat stap drie dieper in op wat er precies verkeerd is gegaan bij de productie van de klank. Dat betekent dat we gedetailleerd de articulatorische veranderingen specificeren die tot het ontstaan van de fout hebben bijgedragen - deze stap is dus van het grootste belang voor de didactiek van de uitspraak.

Zoals het onderzoek van de auteur heeft getoond, kan de verandering betrekking hebben op de volgende articulatorische kenmerken van de klinker: oraliteit/ nasaliteit, dorsaliteit, hoogte, positie van de lippen, duur (kwantiteit) en spanning (kwaliteit). Ook kunnen naast of in plaats van de juiste klinkers andere klanken worden toegevoegd of gerealiseerd onder invloed van de spelling (zie voorbeelden $10 \mathrm{t} / \mathrm{m} 12$ in de tabel hieronder). Het aantal veranderingen binnen hetzelfde proces (stap 2) kan verschillend zijn, zoals de onderstaande voorbeelden illustreren:

1. Als $[\mathrm{y}]$ door $[\mathrm{u}]$ vervangen wordt, dan hebben we met klinkersubstitutie te makendoor één articulatorische verandering: de dorsaliteit van de klinker wordt veranderd (i.p.v het voorgedeelte van het dorsum doet het achtergedeelte mee bij de articulatie) en de overige kenmerken (oraliteit, hoogte, positie van de lippen, duur, spanning) blijven behouden;

${ }^{7}$ Dit proces wordt vooral daar toegepast, waar de spreker (nog) niet in staat is om de spanning van Nederlandse [e], [y] en [o] te realiseren en hij imiteert de spanning door invoeging van een glijklank [j] of [w]. 
2. Als $[y]$ door $[\mathrm{f}]$ vervangen wordt, dan hebben we ook met klinkersubstitutie te doen maar met twee articulatorische veranderingen tot gevolg: positie van de lippen en spanning.

In het corpus heeft de auteur éénvoudige, tweevoudige, drievoudige en viervoudige verandering van articulatorische kenmerken kunnen vaststellen, d.w.z. het aantal articulatorische kenmerken die de verandering ondergingen, bedroeg van één $\mathrm{t} / \mathrm{m}$ vier$^{8}$. In de onderstaande tabel worden alle soorten éénvoudige veranderingen besproken:deze bestaan zelfstandig, maar vormen ook de basis voor verschillende combinaties. Telkens zijn in de tabel voorbeelden toegevoegd.

Tabel 4. Articulatorische veranderingen (stap 3)

\begin{tabular}{|c|c|c|c|}
\hline & Articulatorische verandering & Uitleg & Voorbeelden \\
\hline \multicolumn{4}{|c|}{ Eénvoudige verandering } \\
\hline 1. & lengteverlies & $\begin{array}{l}\text { een lange klinker wordt kort } \\
\text { uitgesproken }\end{array}$ & ------ \\
\hline 2. & lengteverwerving & $\begin{array}{l}\text { een korte klinker wordt lang } \\
\text { uitgesproken }\end{array}$ & ----- \\
\hline 3. & verkorting & $\begin{array}{l}\text { een lange variant van de } \\
\text { klinker wordt korter uit- } \\
\text { gesproken (en de kwaliteit } \\
\text { blijft daarbij onveranderd) }\end{array}$ & $\begin{array}{l}{[\mathrm{i}:] \rightarrow[\mathrm{i}]} \\
{[\mathrm{a} .] \rightarrow[\mathrm{a}]}\end{array}$ \\
\hline 4. & verlenging & $\begin{array}{l}\text { een korte variant van de } \\
\text { klinker wordt langer uit- } \\
\text { gesproken (en de kwaliteit } \\
\text { blijft daarbij onveranderd) }\end{array}$ & [a.] $\rightarrow$ [a:] \\
\hline 5. & kwaliteitsverlies & $\begin{array}{l}\text { een gespannen klinker } \\
\text { wordt zonder spanning } \\
\text { gerealiseerd }\end{array}$ & [i] $\rightarrow$ [I] \\
\hline 6. & kwaliteitsverwerving & $\begin{array}{l}\text { een ongespannen klinker } \\
\text { wordt met spanning uitge- } \\
\text { sproken }\end{array}$ & {$[\mathrm{I}] \rightarrow[\mathrm{i}]$} \\
\hline 7. & dorsaliteitverandering & $\begin{array}{l}\text { een andere gedeelte van } \\
\text { de tong doet mee aan de } \\
\text { articulatie }\end{array}$ & 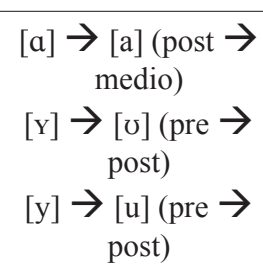 \\
\hline 8. & hoogteverandering & $\begin{array}{l}\text { de verticale beweging van } \\
\text { de tong wordt veranderd }\end{array}$ & $\begin{array}{c}{[\mathrm{y}] \rightarrow[\varnothing] \text { (hoog } \rightarrow} \\
\text { middenhoog) }\end{array}$ \\
\hline
\end{tabular}

${ }^{8}$ Het valt niet uit te sluiten dat voor andere taalparen het aantal veranderingen nog groter kan worden. 


\begin{tabular}{|c|c|c|c|}
\hline 9. & verandering van lippenpositie & $\begin{array}{l}\text { de positie van lippen wordt } \\
\text { veranderd }\end{array}$ & 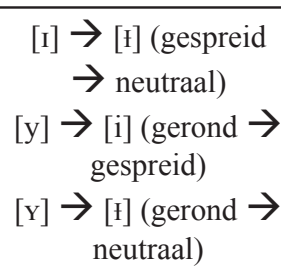 \\
\hline 10. & glijklankepenthese & $\begin{array}{l}\text { voor of na een klinker wordt } \\
\text { een glijklank toegevoegd }\end{array}$ & $\begin{aligned} {[\mathrm{e}] } & \rightarrow[\mathrm{j}]+[\mathrm{e}] \\
{[\mathrm{y}] } & \rightarrow[\mathrm{j}]+[\mathrm{y}]\end{aligned}$ \\
\hline 11. & klinkerepenthese & $\begin{array}{l}\text { voor of na een klinker wordt } \\
\text { een andere klinker toege- } \\
\text { voegd }\end{array}$ & {$[\mathrm{i}] \rightarrow[\mathrm{i}]+[\varepsilon]$} \\
\hline 12. & tweeklankinzet & $\begin{array}{l}\text { i.p.v. een klinker wordt een } \\
\text { tweeklank gerealiseerd }\end{array}$ & $\begin{aligned} {[ə] } & \rightarrow[\text { [ॄi }] \\
{[\varnothing:] } & \rightarrow[\varrho \varnothing] .\end{aligned}$ \\
\hline \multicolumn{4}{|c|}{ Tweevoudige verandering } \\
\hline 13. & $\begin{array}{l}\text { kwaliteits- } \\
\text { en lengteverlies }\end{array}$ & $5+1$ & $\begin{aligned} {[\mathrm{e}:] } & \rightarrow[\varepsilon] \\
{[\mathrm{o}:] } & \rightarrow[\mathrm{o}] \\
{[\mathrm{y}:] } & \rightarrow[\mathrm{y}] \\
{[\mathrm{u}:] } & \rightarrow[\mathrm{v}] \\
{[\mathrm{i}] } & \rightarrow[\mathrm{I}]\end{aligned}$ \\
\hline 14. & $\begin{array}{l}\text { dorsaliteitverandering } \\
+ \text { kwaliteitsverlies }\end{array}$ & $7+5$ & $\begin{array}{l}{[\mathrm{y}] \rightarrow[\mathrm{v}]} \\
{[\mathrm{u}] \rightarrow[\mathrm{y}]}\end{array}$ \\
\hline 15. & $\begin{array}{l}\text { dorsaliteitverandering } \\
+ \text { glijklankepenthese }\end{array}$ & $7+10$ & {$[\mathrm{y}] \rightarrow[\mathrm{j}]+[\mathrm{u}]$} \\
\hline 16. & $\begin{array}{l}\text { hoogteverandering } \\
+ \text { verkorting/verlenging }\end{array}$ & $8+3 / 4$ & $\begin{array}{l}{[\mathrm{e}:] \rightarrow[\mathrm{i}]} \\
{[\varnothing:] \rightarrow[\mathrm{y}]} \\
{[\mathrm{i}] \rightarrow[\mathrm{e} .]}\end{array}$ \\
\hline 17. & $\begin{array}{l}\text { verandering van lippenpositie } \\
+ \text { kwaliteitsverlies }\end{array}$ & $9+5$ & $\begin{array}{l}{[\mathrm{i}] \rightarrow[\mathrm{f}]} \\
{[\mathrm{y}] \rightarrow[\mathrm{f}]}\end{array}$ \\
\hline \multicolumn{4}{|c|}{ Drievoudige verandering } \\
\hline 18. & $\begin{array}{l}\text { dorsaliteitverandering } \\
+ \text { kwaliteit- en lengteverlies }\end{array}$ & $7+5+1$ & $\begin{array}{l}{[\mathrm{y}:] \rightarrow[\mathrm{v}]} \\
{[\mathrm{u}:] \rightarrow[\mathrm{y}]} \\
{[\varnothing:] \rightarrow[\mathrm{v}]}\end{array}$ \\
\hline 19. & $\begin{array}{l}\text { verandering van lippenpositie } \\
+ \text { kwaliteit- en lengteverlies }\end{array}$ & $9+5+1$ & $\begin{array}{l}{[\mathrm{y}:] \rightarrow[\mathrm{f}]} \\
{[\mathrm{i}:] \rightarrow[\mathrm{f}]} \\
{[\varnothing:] \rightarrow[\mathrm{f}]} \\
{[\varnothing] \rightarrow[\varepsilon]}\end{array}$ \\
\hline
\end{tabular}




\begin{tabular}{|c|c|c|c|}
\hline 20. & $\begin{array}{l}\text { kwaliteit- en lengteverlies } \\
+ \text { glijklankepenthese }{ }^{2}\end{array}$ & $5+1+10$ & $\begin{array}{l}{[\mathrm{e}:] \rightarrow[\varepsilon]+[\mathrm{j}]} \\
{[\mathrm{o} .] \rightarrow[0]+[1]} \\
{[\mathrm{e}:] \rightarrow[\mathrm{j}]+[\varepsilon]}\end{array}$ \\
\hline \multicolumn{4}{|c|}{ Viervoudige verandering } \\
\hline 21. & $\begin{array}{l}\text { hoogteverandering } \\
+ \text { kwaliteit- en lengteverlies } \\
+ \text { klinkerepenthese }\end{array}$ & $8+5+1+11$ & {$[\mathrm{u}:] \rightarrow[0]+[\varepsilon]$} \\
\hline 22. & $\begin{array}{l}\text { verandering van lippenpositie } \\
\text { + kwaliteit- en lengteverlies } \\
\text { + glijklankpenthese }\end{array}$ & $9+5+1+10$ & {$[\varnothing:] \rightarrow[\varepsilon]+[\mathrm{w}]$} \\
\hline
\end{tabular}

\subsection{Stap 4}

Terwijl de analyse in het kader van stappen 2 en 3 op het niveau van de afzonderlijke klinker doorgevoerd werd, wordt in de laatste stap rekening gehouden met alle extrasegmentale factoren die invloed kunnen hebben op de foutieve uitspraak van een klinker. Tot die groep worden o.a. de volgende factoren gerekend: spelling, invloed van andere vreemde talen, klemtoon en intonatie. ${ }^{10}$ Wat de spelling betreft, hier vooral de spelling van de moedertaal een rol (bijvoorbeeld het woord euro wordt in de Nederlandse uitspraak van Pools- of Duitstalige personen resp. op z'n Pools $-[\varnothing:] \rightarrow[\varepsilon]+[w]-$ of op zijn Duits $-[\varnothing:] \rightarrow[$ oy $]$ - gerealiseerd). Toch kan ook de invloed vanuit de doeltaal en verschillende vroeger of parallel geleerde vreemde talen niet buiten beschouwing worden gelaten (bijvoorbeeld de klinker [o] in het woord over en de klinker [i] in het woord advies worden resp. als [o] $+[\mho]$ en [ar] uitgesproken onder invloed (van de spelling) van het Engels). Foutieve klemtoon in het woord of intonatie in de zin kan op zijn beurt bijdragen tot te korte of te lange duur van de klinker (bijv. onjuiste klemtoon in woorden die op de syllabe -aar eindigen, veroorzaakt verkorting van [a] in de deze syllabe).

\subsection{Vergelijkende analyse van de uitgekozen fout in de bestaande classificatie en de classificerend-analytische aanpak}

Ter afsluiting klasseren en analyseren we vijf typische uitspraakfouten op het gebied van klinkers, respectievelijk volgens de bestaande classificaties en volgens de nieuwe aanpak. De onderstaande tabellen laten duidelijk zien dat de classificerend-analytische aanpak de fout grondiger en veelzijdiger benadert, wat ook vanuit het gezichstpunt van de didactiek van de uitspraak belangrijk is. De analyse

${ }^{9}$ Dit soort verandering komt voor als de spreker de spanning van de Nederlandse lange [e:] of [o] tracht te imiteren.

${ }^{10}$ Ook hier mag de lijst van factoren niet als volledig worden beschouwd. 
van de fout is van modulair karakter en de afzonderlijke modules kunnen worden afgestemd op de behoeften van de leerders (bijv. op hun fonetische voorkennis) en de cursus.

4.5.1 Nederlandse [e.] wordt vervangen door Poolse $[\varepsilon]$

\begin{tabular}{|c|c|c|c|c|c|}
\hline Weinreich & $\begin{array}{c}\text { Moulton } \\
\text { Stockwell en } \\
\text { Bowen } \\
\text { Tesch }\end{array}$ & Szulc & Kühn & \multicolumn{2}{|c|}{$\begin{array}{c}\text { Classificerend-analytische } \\
\text { aanpak }\end{array}$} \\
\hline \multirow[t]{4}{*}{$\begin{array}{c}\text { under- } \\
\text { differentiation }\end{array}$} & $\begin{array}{l}\text { fonologische } \\
\text { fout }\end{array}$ & $\begin{array}{l}\text { fonologische } \\
\text { fout }\end{array}$ & $\begin{array}{l}\text { kwaliteits- } \\
\text { verlies }\end{array}$ & stap 1 & $\begin{array}{c}\text { fonologische } \\
\text { of fonetische } \\
\text { fout }\end{array}$ \\
\hline & & $\begin{array}{c}\text { kan extra } \\
\text { grafemisch } \\
\text { worden } \\
\text { ondersteund }\end{array}$ & & stap 2 & $\begin{array}{l}\text { klinker- } \\
\text { substitutie }\end{array}$ \\
\hline & & & & stap 3 & $\begin{array}{c}\text { kwaliteit- } \\
\text { en lengteverlies }\end{array}$ \\
\hline & & & & stap 4 & $\begin{array}{l}\text { kan extra } \\
\text { grafemisch } \\
\text { worden } \\
\text { ondersteund } \\
\text { (invloed } \\
\text { vanuit } \\
\text { moedertaal) }\end{array}$ \\
\hline
\end{tabular}

4.5.2 Nederlandse [y:] wordt vervangen door Poolse[v]

\begin{tabular}{|c|c|c|c|c|c|}
\hline Weinreich & $\begin{array}{c}\text { Moulton } \\
\text { Stockwell en } \\
\text { Bowen } \\
\text { Tesch }\end{array}$ & Szulc & Kühn & \multicolumn{2}{|c|}{$\begin{array}{c}\text { Classificerend-analytisch } \\
\text { aanpak }\end{array}$} \\
\hline $\begin{array}{c}\text { under-differ- } \\
\text { entiation }\end{array}$ & $\begin{array}{c}\text { fonetische } \\
\text { fout }\end{array}$ & $\begin{array}{c}\text { fonetische } \\
\text { fout }\end{array}$ & $\begin{array}{c}\text { subsitutie? } \\
\text { kwaliteits- } \\
\text { verlies? }\end{array}$ & stap 1 & $\begin{array}{c}\text { fonetische } \\
\text { fout }\end{array}$ \\
\hline & $\begin{array}{c}\text { kan extra } \\
\text { grafemisch } \\
\text { worden on- } \\
\text { dersteund }\end{array}$ & & stap 2 & $\begin{array}{c}\text { klinker- } \\
\text { substitutie }\end{array}$ \\
\hline & & & stap 3 & $\begin{array}{c}\text { verandering } \\
\text { dorsaliteit- } \\
\text { en lengtever- } \\
\text { lies }\end{array}$ \\
\hline
\end{tabular}




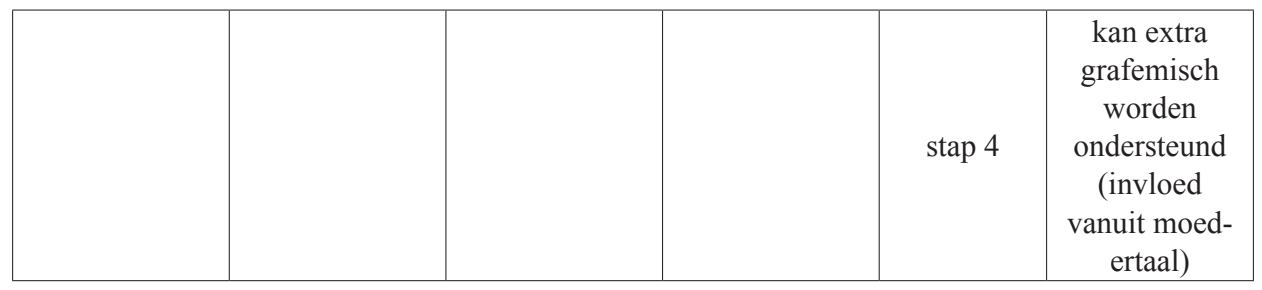

4.5.3 Nederlandse [e.] wordt vervangen door Poolse $[\varepsilon]+[\mathrm{j}]$

\begin{tabular}{|c|c|c|c|c|c|}
\hline Weinreich & $\begin{array}{c}\text { Moulton } \\
\text { Stockwell en } \\
\text { Bowen } \\
\text { Tesch }\end{array}$ & Szulc & Kühn & \multicolumn{2}{|c|}{$\begin{array}{c}\text { Classificerend-analytische } \\
\text { aanpak }\end{array}$} \\
\hline $\begin{array}{c}\text { under-differ- } \\
\text { entiation }\end{array}$ & $\begin{array}{c}\text { fonetische } \\
\text { fout }\end{array}$ & $\begin{array}{c}\text { fonetische } \\
\text { fout }\end{array}$ & klanksplitsing & stap 1 & $\begin{array}{c}\text { fonetische } \\
\text { fout }\end{array}$ \\
\hline & $\begin{array}{c}\text { kan extra } \\
\text { grafemisch } \\
\text { worden on- } \\
\text { dersteund }\end{array}$ & & stap 2 & $\begin{array}{c}\text { klinker- } \\
\text { substitutie } \\
\text { + klinker- } \\
\text { uitbreiding }\end{array}$ \\
\hline & & & stap 3 & $\begin{array}{c}\text { kwaliteit-en } \\
\text { lengteverlies }\end{array}$ \\
\hline & & stap 4 & $\begin{array}{c}\text { wordt } \\
\text { toegepast om } \\
\text { spanning te } \\
\text { immiteren }\end{array}$ \\
\hline
\end{tabular}

4.5.4 Nederlandse NL [ø:] wordt vervangen door [əI]

\begin{tabular}{|c|c|c|c|c|c|}
\hline Weinreich & $\begin{array}{c}\text { Moulton } \\
\text { Stockwell en } \\
\text { Bowen } \\
\text { Tesch }\end{array}$ & Szulc & Kühn & \multicolumn{2}{|c|}{$\begin{array}{c}\text { Classificerend-analytische } \\
\text { aanpak }\end{array}$} \\
\hline $\begin{array}{c}\text { under-diffe- } \\
\text { rentiation } \\
(?)\end{array}$ & $\begin{array}{c}\text { fonetische } \\
\text { fout }\end{array}$ & fonetische fout & substitutie & stap 1 & $\begin{array}{c}\text { onetische } \\
\text { fout }\end{array}$ \\
\hline & & $\begin{array}{c}\text { kan extra grafe- } \\
\text { misch worden } \\
\text { ondersteund }\end{array}$ & stap 2 & $\begin{array}{c}\text { klinker- } \\
\text { substitutie }\end{array}$ \\
\hline & & stap 3 & $\begin{array}{c}\text { inzet van een } \\
\text { tweeklank }\end{array}$ \\
\hline
\end{tabular}




\begin{tabular}{|c|c|c|c|c|c|}
\hline & & & & invloed van \\
een andere \\
vreemde taal \\
(Duits) en \\
zijn spelling \\
\end{tabular}

4.5.5 Nederlandse [a:] wordt vervangen door Poolse PL [a]

\begin{tabular}{|c|c|c|c|c|c|}
\hline Weinreich & $\begin{array}{c}\text { Moulton } \\
\text { Stockwell en } \\
\text { Bowen } \\
\text { Tesch }\end{array}$ & Szulc & \multicolumn{2}{|c|}{ Kühn } & \multicolumn{2}{|c|}{$\begin{array}{c}\text { Classificerend-analytische } \\
\text { anpak }\end{array}$} \\
\hline entiation & $\begin{array}{c}\text { fonologische } \\
\text { fout } \\
\text { fonologische } \\
\text { fout }\end{array}$ & substitutie? & stap 1 & $\begin{array}{c}\text { fonologische } \\
\text { of fonetische } \\
\text { fout }\end{array}$ \\
\hline & $\begin{array}{c}\text { kan extra } \\
\text { grafemisch } \\
\text { worden on- } \\
\text { dersteund }\end{array}$ & & stap 2 & $\begin{array}{c}\text { klinker-modi- } \\
\text { ficatie }\end{array}$ \\
\hline & & & stap 3 & verkorting \\
\hline & & & stap 4 & $\begin{array}{c}\text { kan extra } \\
\text { grafemisch } \\
\text { worden onder- } \\
\text { steund (inv- } \\
\text { loed vanuit } \\
\text { moedertaal) }\end{array}$ \\
\hline
\end{tabular}

\section{Conclusies en postulaten voor verder onderzoek}

De centrale vraag die in deze bijdrage gesteld werd, betrof mogelijkheden om uitspraakfouten te classificeren en te analyseren voor didactische doeleinden. Het overzicht van enkele klassieke foutenclassificaties bracht enkele tekortkomingen aan het licht (vergelijking van fonologische systemen als basis, oppervlakkigheid, geen rekening houden met invloed van de spelling, suprasegmentale factoren en invloed vanuit andere vreemde talen). De bruikbare aspecten van bestaande classificaties benuttend en rekening houdend met hun tekorten, is hier vervolgens een nieuwe aanpak uitgewerkt met het oog op didactische toepasbaarheid. Daarbij is een gedetailleerde analyse in vier stappen voorgesteld, met enkele classificatieopties per stap, eerst top-down en dan met aandacht voor bijkomende factoren zoals 
grafemiek, suprasegementale factoren, invloed van andere talen. Het didactisch uitgangspunt heeft geleid tot de keuze voor een modulair karakter van de aanpak, die het mogelijk maakt rekening te houden met het niveau van de groep en haar (fonetische) voorkennis van de doelgroep. De analyse van enkele vaak voorkomende fouten inde uitspraak van Nederlandse klinkers bij Poolse leerders toonde inderdaad dat de classificerend-analytische aanpak deze fouten grondiger en veelzijdiger kan behandelen.

Vanzelfsprekend mag het werk aan dit model niet als voltooid worden beschouwd. De aanpak moet verder worden uitgebreid (in de volgende stap met medeklinkers, dan nog met tweeklanken en affricaten) om te komen tot een optimale classificerende beschrijving die een voldoende algemeen is maar toch ook adequaat gespecificiceerd om een bruikbare toepasselijkheid te verzekeren. Verder moet zeker ook de factor auditie erbij betrokken worden, d.w.z. de invloed van de (verkeerde) auditieve perceptie van de uitspraak in de doeltaal. Praktisch vervolgonderzoek in de concrete uitspraakdidactiek is ook noodzakelijk om te bepalen of de aanpak inderdaad van nut zou kunnen zijn in de klassituatie op verschillende niveaus en in het kader van verschillende opleidingsvormen (cursussen NT2, cursussen NVT, universitaire Neerlandistiek extra muros).

\section{Bibliografie}

Baelen, Mélanie, Hiligsmann, Philippe \& Rasier, Laurent (2008): "De assimilatie van stem in de tussentaal van Franstalige leerders van het Nederlands". n/f, 9-29.

Beheydt, Ludo (2011): “Uitspraakonderwijs Nederlands en normativiteit”. In: Rasier, Laurent e.a.: Lage Landen Studies 2. Gent: Academia Press, 101-118.

Beheydt, Ludo, Dirven, René \& Kaunzner, Ulrike A. (1999): Uitspraak Nederlands. Leuven/Amersfoort: Acco.

Blomme, Ines, Nordin, Annelies \& Potargent, Johanna (2009): Nu versta ik je! Uitspraak Nederlands voor anderstaligen. Leuven: Acco.

Bossers, Bart (ed.) (2007): Vakwerk 4. Achtergronden van de NT2-lespraktijk. Lezingen studiemiddag Uitspraak en Verstavaardigheid juni 2007. Amsterdam: BV NT2.

Corder, Pit (1967): “The significance of learners' errors”. In: International Review of Applied Linguistics 5: 160-170.

Corder, Pit (1981): Error Analysis and Interlanguage. Oxford: Oxford University Press.

Czerwonka, Zuzanna (2010): "De vocaalsystemen van het Pools, Duits en Nederlands-polyconfrontatieve analyse en didactische implicaties". In: Engelbrecht, Wilken \& Hamers, Bas: Neerlandistische ontmoetingen: Trefpunt Olomouc. Olomouc: Univerzita Palackého v Olomouci, 255-262.

Czerwonka, Zuzanna (2011): "Die Anwendung der polykonfrontativen Methode in der phonetischen Beschreibung - am Beispiel der Vokalsysteme des Polnischen, Deutschen ind Niederländischen”. In: Bartoszewicz, Iwona, Szczęk, Joanna \& Tworek, Artur: Germanistische Linguistik im interdisziplinären Gefüge. Wrocław: Atut / Dresden: Neisse Verlag, 167-173.

Czerwonka, Zuzanna (2012): "Die prädorsal-gerundeten niederländischen Vokale als Aussprachproblem für polnische und deutsche Studierende der Niederlandistik - eine Signaluntersuchung". 
In: Błachut, Edyta \& Gołębiowski, Adam: Motoren der heutigen germanistischen Linguistik: Akten der 22. internationalen Linguistenkonferenz, Karpacz 10-12.10.2011. Wrocław: Atut / Dresden: Neisse Verlag, 27-37.

Czerwonka, Zuzanna (2012): "Nederlandse geronde voorklinkers als fonetisch probleem voor Poolse ed Duitse modedertaalsprekers - een theoretisch en praktisch overzicht". In: Neerlandica Wratislaviensia 21: 45-59.

Czerwonka, Zuzanna (2013): “(Aus)Sprache im Unterricht: die prädorsalen ungerundeten Vokale der Niederländischen als Ausspracheproblem für polnische Muttersprachler- eine Signaluntersuchung”. In: Błachut, Edyta \& Gołębiewski, Adam: Sprache in Wissenschaft und Unterricht: Akten des 23. internationalen Linguistenkonferenz Karpacz 14-16.05.2012. Wrocław: Atut / Dresden: Neisse Verlag, 58-67.

Czerwonka, Zuzanna (2015): "De »functional load« en moelijkheidsgraad van een klank versus het onderwijs in de Nederlandse uitspraak". In: Brünner Beiträge zur Germanistik und Nordistik 29, 2: 109-120.

Heuven, Vincent van (2011): "De klinkers in het Nederlands van Turkse immigranten”. In: Rasier, Laurent e.a.: Lage Landen Studies 2. Gent: Academia Press, 9-24.

Heuven, Vincent van \& Velde, Hans van de (2010): "De uitspraak van het hedendags Nederlands in de Lage Landen”. In: Fenoulhet, Jane \& Renkema, Jan (ed.): Lage Landen Studies 1. Gent: Academia Press, 183-210.

Hiligsmann, Philippe (1998): "De uitspraak van Franstalige leerders van het Nederlands: een theoretische en didactische benadering”. In: Neerlandica Wratislaviensis 10: 171-182.

Hiligsmann, Philippe (1999): "Uitspraakvaardigheid van Franstalige leerders van het Nederlands: een ondergeschoven kind?" In: Handelingen de Koninklijke Zuid-Nederlandse Maatschappij voor Taal-en Letterkunde en Geschiedenis 52: 157-167.

Hiligsmann, Philippe \& Rasier, Laurent (2006): Uitspraakleer Nederlands voor Franstaligen. Waterloo: Wolters-Plantyn.

James, Allan (ed.) (1991): Levende Talen Magazine 78 (466).

Kampen, Hinke van e.a. (2011): Uitspraaktrainer in de les. Uitspraakverbetering voor anderstaligen. Amsterdam: Boom.

Kostelecká, Marta (2010). “Articulatory settings van vocalen in het Tsjechisch en het Nederlands". In: Engelbrecht, Wilken \& Hamers, Bas (ed.): Neerlandistische ontmoetingen: Trefpunt Olomouc. Olomouc: Univerzita Palackého v Olomouci, 263-273.

Kostelecká, Marta (2012): “Articulatory settings in het Nederlands en in het Tsjechisch”. In: Brünner Beiträge zur Germanistik und Nordistik 26, 1-2: 11-23.

Kühn, Antje (2010): Kontrastive Phonetik der romanischen Sprachen. Dresden: Diskurs-Verlag.

Lowie, Wander (2004): “De zin en onzin van uitspraakonderwijs". In: Levende Talen 5, 1: 3-12.

Moulton, William G. (1962): "Towards a Classification of Pronunciation Errors". In: The Modern Language Journal 46, 1: 101-108.

Nagy, Roland (2006): "Fonetica, fonologie en uitspraakonderwijs". In: Praagse perspectieven 4: 99-108.

Nagy, Roland (2015): “Op weg naar een doelgerichter universitair NT2-uitspraakonderwijs. Contrastieve uitspraakanalyse Hongaars-Nederlands". In: Taal Toetsen: 161-187.

Prędota, Stanisław (1971): "Zur Untersuchung der phonetischen Interferenz”. In: Germanica Wratislaviensia 15: 147-153.

Rasier, Laurent (2008): "Van uitspraakonderzoek naar uitspraakonderwijs. Implicaties van het onderzoek naar uitspraakverwerving voor de onderwijspraktijk". In: Toegepaste taalwetenschap in artikelen 80: 29-39.

Rasier, Laurent (2011): “Uitspraakonderwijs Nederlands aan anderstaligen”. In: Rasier, Laurent e.a.: Lage Landen Studies 2. Gent: Academia Press, 119-142. 
Rasier, Laurent e.a. (2011): Lage Landen Studies 2. Gent: Academia Press.

Rausch, Rudolf \& Rausch, Ilka (2002): Deutsche Phonetik für Ausländer. Leipzig/Berlin/München: Langenscheidt.

Selinker, Larry (1972): "Interlanguage”. In: International Review of Applied Linguistics 10: 209231.

Sleeuwen, Gabi van \& Spaan, Anneloes (2013): Nu versta ik je! Uitspraak Nederlands voor anderstaligen. Leuven: Acco.

Smakman, Dirk (2006): Standard Dutch in the Netherlands. A sociolinguistic and phonetic description. PhD Dissertation University of Nijmegen. Utrecht: LOT.

Smakman, Dirk (2016): "Pronunciation: Teach or ignore?". In: Arnhem, Max van \& Smakman, Dik (ed.): Proceedings Van Schools tot Scriptie II: een colloquium over universitair taalvaardigheidsonderwijs Universiteit Leiden, 4 juli 2014. Leiden: Leiden University Repository, 61-65.

Spillner, Bernd (1991): Error Analysis. Amsterdam/Philadelphia: Benjamins.

Stockwell, Robert \& Bowen, Donald (1975): The Sounds of English and Spanish. Chicago/London: University of Chicago Press.

Szulc, Aleksander (1973): "Die Hauptypen der phonischen Interferenz". In: Zeitschrift für Phonetik und Kommunikationsforschung 26: 111-119.

Tesch, Gerd (1978): Linguale Interferenz: theoretische, terminologische und methodologische Grundfragen zu ihrer Erforschung. Tübingen: Narr.

Timmermans, Bernadette (2008): Klink klaar. Uitspraak- en intonatiegids voor het Nederlands. Davidsfonds, Leuven.

Veen, Chris van e.a. (2011): Goed gezegd: uitspraak voor anderstaligen. Antwerpen: Wpg Uitgevers $\mathrm{Be}$ - Algemeen.

Vriendt, Sera de (1993): "Uitspraakcorrectie, in het bijzonder bij sprekers van Slavische talen die Nederlands leren”. In: Prędota, Stanisław: Handelingen Regionaal Colloquium Neerlandicum. Wrocław: Wydawnictwo Uniwersytetu Wrocławskiego, 313-319.

Weinreich, Uriel (1953): Languages in Contact: Findings and Problems. The Hague/Paris/New York: Mouton.

Weinreich, Uriel (1979): Languages in Contact: Findings and Problems. The Hague/Paris/New York: Mouton.

Zuzanna Czerwonka-Wajda $(* 1985)$ promoveerde aan de Universiteit van Wroclaw op het proefschrift De vocaalsystemen van het Pools, Duits en Nederlands - vergelijkende analyse en didactische implicaties. Haar onderzoek richt zich vooral op de didactiek van uitspraak van het Nederlands, vergelijkende taalkunde en multilingualisme van volwassenen.

e-mail: zuzanna.czerwonka@uwr.edu.pl

Neerlandica Wratislaviensia 27, 2017

(C) for this edition by CNS 